\title{
Cytokine Profiles and Cell Proliferation Responses to Truncated ORF2 Protein in Iranian Patients Recovered from Hepatitis E Infection
}

\author{
Reza Taherkhani, ${ }^{1,2}$ Fatemeh Farshadpour, ${ }^{1,2}$ Manoochehr Makvandi, ${ }^{3}$ \\ Hamid Rajabi Memari, ${ }^{4}$ Ali Reza Samarbafzadeh, ${ }^{3}$ Nasrin Sharifi, ${ }^{5}$ Behrouz Naeimi, ${ }^{1,2}$ \\ Saeed Tajbakhsh, ${ }^{1,2}$ and Samad Akbarzadeh ${ }^{2}$ \\ ${ }^{1}$ Department of Microbiology and Parasitology, School of Medicine, Bushehr University of Medical Sciences, Bushehr 7514633341, Iran \\ ${ }^{2}$ Persian Gulf Tropical Medicine Research Centre, Bushehr University of Medical Sciences, Bushehr 7514633341, Iran \\ ${ }^{3}$ Health Research Institute, Infectious and Tropical Disease Research Centre, Ahvaz Jundishapur University of Medical Sciences, \\ Ahvaz 6135715794, Iran \\ ${ }^{4}$ Department of Agronomy and Plant Breeding, Faculty of Agriculture, Ahvaz Shahid Chamran University, Ahvaz 6135715794, Iran \\ ${ }^{5}$ Department of Nutrition, School of Medicine, Kashan University of Medical Sciences, Kashan 8715988141, Iran
}

Correspondence should be addressed to Fatemeh Farshadpour; f.farshadpour@yahoo.com

Received 25 June 2015; Revised 23 August 2015; Accepted 2 September 2015

Academic Editor: Susana A. Laucella

Copyright (C) 2015 Reza Taherkhani et al. This is an open access article distributed under the Creative Commons Attribution License, which permits unrestricted use, distribution, and reproduction in any medium, provided the original work is properly cited.

Background. The aim of this study was to evaluate hepatitis E virus (HEV) specific cellular immune responses to truncated ORF2 protein in Iranian patients recovered from HEV infection. Information about HEV-specific immune responses could be useful in finding an effective way for development of HEV vaccine. Methods. A truncated form of HEV ORF2 protein containing amino acids 112-608 was used to stimulate peripheral blood mononuclear cells (PBMCs) separated from HEV-recovered and control groups. Finally, the levels of four cytokines, IFN- $\gamma$ ELISPOT, and cell proliferative responses following stimulation with the truncated ORF2 protein were assessed in the both groups. Results. The truncated ORF2 protein was able to induce IFN- $\gamma$ ELISPOT and cell proliferation responses and to produce significant amounts of IFN- $\gamma$ and IL-12 cytokines, but low amounts of IL-10 and IL-4 cytokines in vitro. These responses were significantly higher in the recovered group compared to the control group. These results indicate the antigenic nature of the truncated ORF2 protein and production of T helper type 1 cytokines. Conclusion. The truncated ORF2 protein can effectively induce significant cellular immune responsesand can be introduced as a potential vaccine candidate. However, further studies are required to evaluate this protein in vivo.

\section{Introduction}

Hepatitis $E$ virus (HEV) is a nonenveloped virus with a nonsegmented positive-sense RNA genome containing three open reading frames (ORFs) $[1,2]$. HEV belongs to the family Hepeviridae and the genus Hepevirus [3]. The genus Hepevirus has two species including mammalian HEV and avian HEV. The mammalian HEV, which infects humans and several mammalians, is classified into four major genotypes, namely, genotypes 1, 2, 3, and 4 [4]. The HEV genotypes share highly conserved immunodominant domains that are serologically cross-reactive [5].
HEV causes large outbreaks of acute hepatitis in developing countries where sanitary conditions are inadequate and the infection is enterically transmitted by the fecal-oral route especially contaminated water $[6,7]$. The zoonotic spread of the disease is also possible especially in developed countries where the sporadic cases of the infection have been reported $[2,4]$. Although the infection is usually asymptomatic or acute self-limiting in general population, but it can progress to lethal fulminant hepatitis in pregnant women and chronic hepatitis in immunosuppressed and organ transplant patients $[5,8]$. The general mortality rate of HEV infection is between 
$1 \%$ and $15 \%$, and this level may reach up to $30 \%$ due to fulminate hepatic failure during pregnancy, which may lead to high rate of spontaneous abortion and premature birth $[5,9]$. Consequently, HEV has become a serious publichealth concern especially in endemic areas, and control and prevention of this infection are necessary [2]. So far, no effective treatment or commercial vaccines for $\mathrm{HEV}$ infection are available, and the only way to reduce incidence of the infection is prevention $[2,10]$.

Currently, the focus for development of HEV vaccine is on ORF2 protein. ORF2 encodes capsid protein that comprises 660 amino acids. HEV capsid protein has several immune-dominant conserved epitopes that can induce longlived immunity; therefore, it has been studied for vaccine development [11]. However, the full-length capsid protein is not suitable for vaccine production. Since it is hydrophobic and insoluble and its immunoreactive epitopes are masked, much attention has been drawn to the truncated or short forms of ORF2 protein as protective vaccines [12, 13].

The truncated ORF2 protein, containing amino acids 112 to 660 of the ORF2 protein, self assembles into virus-like particles and can induce strong immunity [14]. Moreover, 52 amino acids from the $\mathrm{C}$ terminus and 111 amino acids from the $\mathrm{N}$ terminus of the ORF2 protein do not have any antigenic domain, and most antigenic domains have located within 268 amino acids of $\mathrm{C}$ terminal of the ORF2 protein [5]. Also, the truncated ORF2 protein containing amino acids 459 to 607 is needed to produce anti-HEV antibodies; therefore, it seems that antigenic epitopes are conformational [5]. Anti$\mathrm{HEV}$ antibodies from all genotypes cross-react with the ORF2 protein of genotype 1 [5]; therefore, production of a broadly protective vaccine seems to be possible by expression the truncated ORF2 protein of genotype 1 [13].

In the present study, the cellular immune responses to the truncated ORF2 protein were evaluated in the peripheral blood mononuclear cells (PBMCs) of individuals recovered from hepatitis E infection.

\section{Materials and Methods}

2.1. Ethics Statement. This study (with research project number D/574) was approved by the Jundishapur University Ethical Committee, and informed consent was taken from all the participants.

2.2. Study Group. Forty anti-HEV IgG positive subjects (24, $60 \%$ males and $16,40 \%$ females; mean age \pm SD, $35.12 \pm 9.66$ years) and forty-eight anti-HEV IgG negative subjects (28, $58.3 \%$ males and $20,41.7 \%$ females; mean age \pm SD, $33.06 \pm$ 10.70 years) were randomly selected as HEV-recovered and control groups to study the immunogenicity of the truncated ORF2 protein. The presence of anti-HEV IgG antibody was detected by the commercial ELISA kit (HEV IgG ELISA kit, DIA.PRO, Milan, Italy). All the participants were negative for anti-HEV IgM antibody, anti-HAV IgM antibody, anti-HCV antibodies, and hepatitis B surface antigen (HEV IgM ELISA kit, HAV IgM ELISA kit, HCV Ab ELISA kit, HBs Ag ELISA kit, DIA.PRO, Milan, Italy) and had normal ALT level.
2.3. Preparation of Peripheral Blood Mononuclear Cells. Ficoll-Hypaque (Lymphoflot, Biotest Diagnostics, Germany) and density gradient centrifugation method were used to separate peripheral blood mononuclear cells (PBMCs) from $10 \mathrm{~mL}$ heparinized venous blood sample of the each individual. Then the cells were washed twice by RPMI 1640 medium and resuspended in RPMI 1640 plus 10\% FCS (Invitrogen, Carlsbad, CA, USA). Trypan blue staining was used to evaluate the cells viability.

2.4. Preparation of Truncated ORF2 Protein. A truncated form of HEV ORF2 protein containing amino acids 112608 was produced as described previously [15]. Briefly, a truncated ORF2 gene encoding amino acids 112-660 of Sar55 strain from HEV genotype 1 was optimized for expression in E. coli and synthesized and cloned into pBluescript II $\mathrm{SK}(+)$ vector by Biomatik Company (Biomatik Corporation, Cambridge, Canada). The truncated gene was subcloned into expression vector pET-30a(+) and the recombinant plasmid pET30a-ORF2 ${ }_{(\text {a } 112-660)}$ was constructed. Then, a 193-nucleotide fragment was removed from the nucleotide sequence of the truncated ORF2 gene by digestion with NheI restriction enzyme and another truncated form of ORF2 gene encoding amino acids 112-608 was constructed. The recombinant plasmid pET-30a-ORF2 ${ }_{(\text {aa 112-608) }}$ was transformed into E. coli BL21 (DE3) using electroporation. Expression of the truncated ORF2 protein containing amino acids 112608 was induced by adding $1 \mathrm{mM}$ IPTG to the bacterial culture followed by $4 \mathrm{hr}$ incubation at $37^{\circ} \mathrm{C}$. The expressed truncated ORF2 protein was purified by Ni2+-chelate-affinity chromatography (Qiagen, Hilden, Germany). Refolding of the purified protein was done by dialysis in $\mathrm{PBS}+10 \%$ glycerol at $4^{\circ} \mathrm{C}$ for $4 \mathrm{hr}$. Amicon Ultra-4 Centrifugal Filter Unit (EMD Millipore, Billerica, MA, USA) was used to improve the concentration and purity of the target protein. To remove endotoxin contamination that may be obtained during protein purification, endotoxin was extracted from the protein by Toxin Eraser Endotoxin Removal kit (GenScript, Piscataway, NJ, USA).

2.5. Cell Proliferation Assay. The cell proliferation was carried out by the colorimetric assay using MTT (3-(4,5dimethylthiazol-2-yl)-2,5-diphenyl tetrazolium bromide) as described previously [16]. For each sample, approximately $1 \times$ $10^{5} \mathrm{PBMCs} /$ well in RPMI 1640 plus 10\% FCS were added to 3 wells of 96 -well plates in final volume of $180 \mu \mathrm{L} /$ well. The first well was stimulated with $10 \mu \mathrm{g} / \mathrm{mL}$ of truncated ORF2 protein in final volume $20 \mu \mathrm{L}$. $20 \mu \mathrm{L} /$ well of phytohemagglutinin (PHA) $(5 \mu \mathrm{g} / \mathrm{mL}$ ) (Sigma-Aldrich, St. Louis, MO, USA) was used as positive control in the second well and the third well remained unstimulated as negative control. Blanking was done by putting RPMI $1640(20 \mu \mathrm{L})$ alone in the well. The optimal concentrations of truncated ORF2 protein and PHA and the optimum stimulation duration were determined based on preliminary experiments. The plate was incubated in the presence of $5 \% \mathrm{CO}_{2}$ at $37^{\circ} \mathrm{C}$ for 4 days, and then $10 \mu \mathrm{L}$ of MTT solution $(5 \mathrm{mg} / \mathrm{mL})$ was added to each well. After incubation at $37^{\circ} \mathrm{C}$ for $4 \mathrm{hr}$ and centrifugation in $1000 \times \mathrm{g}$ 
TABLE 1: Results of cytokine, lymphocyte proliferation, and ELISPOT assays in response to truncated ORF2 protein in HEV recovered individuals and control group.

\begin{tabular}{lccc}
\hline Parameter & Control group $(n=48)$ & Recovered group $(n=40)$ & $p$ value \\
\hline IFN- $\gamma$ & $17.12 \pm 6.93$ & $143.40 \pm 52.33$ & $<0.001$ \\
IL-12 & $18.33 \pm 9.04$ & $112.75 \pm 43.26$ & $<0.001$ \\
IL-10 & $18.72 \pm 8.55$ & $27.80 \pm 19.55$ & 0.100 (NS) \\
IL-4 & $4.30 \pm 1.53$ & $4.90 \pm 1.49$ & 0.067 (NS) \\
ELISPOT & $4.39 \pm 5.51$ & $65.92 \pm 58.99$ & $<0.001$ \\
Cell proliferation & $1.50 \pm 0.17$ & $2.01 \pm 0.28$ & $<0.001$ \\
\hline
\end{tabular}

Cytokine values are represented as picograms per milliliter $(\mathrm{pg} / \mathrm{mL})$, the results of ELISPOT assay are expressed as spot forming cells per $10^{5}$ cells $\left(\mathrm{SFC} / 10^{5}\right.$ cells), and the results of cell proliferation assay are shown as proliferation index (PI).

All data are shown as mean $\pm \mathrm{SD}$.

NS = nonsignificant.

for $10 \mathrm{~min}$, the supernatant was discarded and $100 \mu \mathrm{L}$ of DMSO was added to each well and mixed by pipetting. The absorbance of the wells was measured using an ELISA reader at $570 \mathrm{~nm}$ within an hour. The results were expressed as proliferation index (PI). PI was defined as OD570 stimulated sample/OD570 unstimulated sample.

2.6. IFN $\gamma$ ELISPOT Assay. The IFN $\gamma$ ELISpot assay was performed by Human IFN- $\gamma$ ELISPOT Ready-SET-Go kit (eBioscience, San Diego, CA, USA) to determine HEVspecific IFN- $\gamma$-producing cells. According to manufacturer's structure, a PVDF bottomed ELISPOT plate (Millipore, Bedford, MA, USA) was coated with Capture Antibody solution $(100 \mu \mathrm{L} /$ well $)$ overnight at $4^{\circ} \mathrm{C}$. For each sample, approximately $1 \times 10^{5}$ PBMCs/well in RPMI 1640 plus $10 \%$ FCS were added to 3 wells of the 96-well ELISPOT plate in final volume of $150 \mu \mathrm{L} /$ well. The first well was stimulated with $10 \mu \mathrm{g} / \mathrm{mL}$ truncated ORF2 protein. Five $\mu \mathrm{g} / \mathrm{mL}$ of PHA was used as positive control in the second well, and the third well remained unstimulated as negative control. The optimal count of PBMC in each well, the optimal concentrations of truncated ORF2 protein and PHA, and the optimum duration of stimulation were determined based on preliminary experiments. The plate was incubated at $37^{\circ} \mathrm{C}$ for $24 \mathrm{hr}$. Then, the cells and medium were removed and the wells were washed 3 times with ELISPOT Wash Buffer. The plate was incubated with Biotinylated Detection Antibody $\left(100 \mu \mathrm{L} /\right.$ each well) at $4^{\circ} \mathrm{C}$ overnight and washed 4 times with ELISPOT Wash Buffer. In the next step, the plate was incubated with $100 \mu \mathrm{L} /$ well of Avidin-Horseradish Peroxidase reagent at room temperature for $45 \mathrm{~min}$ and washed with ELISPOT Wash Buffer and 1x PBS. Finally, the dark purple spots were developed by adding $100 \mu \mathrm{L} /$ well AEC (3-amino-9-ethylcarbazole), followed by incubation at room temperature. The plate was washed 3 times with $200 \mu \mathrm{L} /$ well distilled water and dried at room temperature, and then a dissection stereoscope was used to count the number of spots. The results were shown as spot forming cells (SFCs) per $10^{5}$ cells, while each spot was considered as one HEV-specific IFN- $\gamma$ secreting cell.

2.7. Cytokine Assay. PBMCs of each sample were stimulated with the truncated ORF2 protein $(10 \mu \mathrm{g} / \mathrm{mL})$ at $37^{\circ} \mathrm{C}$. In addition, five $\mu \mathrm{g} / \mathrm{mL}$ PHA was used as positive control. The optimal concentrations of truncated ORF2 protein and PHA and the optimum stimulation duration were determined based on preliminary experiments. Culture supernatants were harvested after 1-2 days and used to measure amounts of four cytokines (IL-4, IL-12 p70, IFN- $\gamma$, and IL-10). Cytokine assay was performed by commercially available ELISA kits (eBioscience, San Diego, CA, USA) according to the manufacturer's instructions. The results were shown as picograms per milliliter $(\mathrm{pg} / \mathrm{mL})$. The limits of sensitivity of the assays were $1.3 \mathrm{pg} / \mathrm{mL}$ for IL- $4,1.0 \mathrm{pg} / \mathrm{mL}$ for IL-10, $2.1 \mathrm{pg} / \mathrm{mL}$ for IL$12 \mathrm{p} 70$, and $0.99 \mathrm{pg} / \mathrm{mL}$ for IFN- $\gamma$.

2.8. Statistical Analysis. SPSS 17 Package program (SPSS Inc., Chicago, USA) was used for statistical analysis, and $p$ values below 0.05 indicated statistical significance. The data were analyzed and compared by the Mann-Whitney $U$ test or independent $t$-test. All data were expressed as mean \pm SD.

\section{Results}

3.1. Cell Proliferative Response to Truncated ORF2 Protein. Proliferation of PBMCs in response to the truncated ORF2 protein was measured in the control and HEV-recovered groups. The cell proliferative responses to truncated ORF2 protein in the control and HEV-recovered groups were $1.50 \pm$ 0.17 and $2.01 \pm 0.28$, respectively. The corresponding figures following stimulation with PHA were $2.91 \pm 0.37$ and $2.81 \pm$ 0.33 in the control and recovered groups, respectively $(p=$ NS). Overall, the recovered group showed significantly higher cell proliferation compared to the control group $(p<0.001)$ (Table 1, Figure 1).

3.2. IFN- $\gamma$ ELISPOT Responses to the Truncated OR2 Protein. The frequencies of IFN- $\gamma$-secreting cells in PBMCs of HEVrecovered and control groups were assessed in response to truncated ORF2 protein by ELISPOT assay. IFN- $\gamma$ ELISPOT responses following stimulation with the truncated ORF2 protein in the control and HEV-recovered groups were $4.39 \pm$ 5.51 and $65.92 \pm 58.99$, respectively. ELISPOT responses to PHA in the control and recovered groups were $223.41 \pm 94.58$ and $228.25 \pm 123.41$, respectively ( $p=$ NS). Overall, IFN- $\gamma$ ELISPOT responses were significantly higher in the recovered 


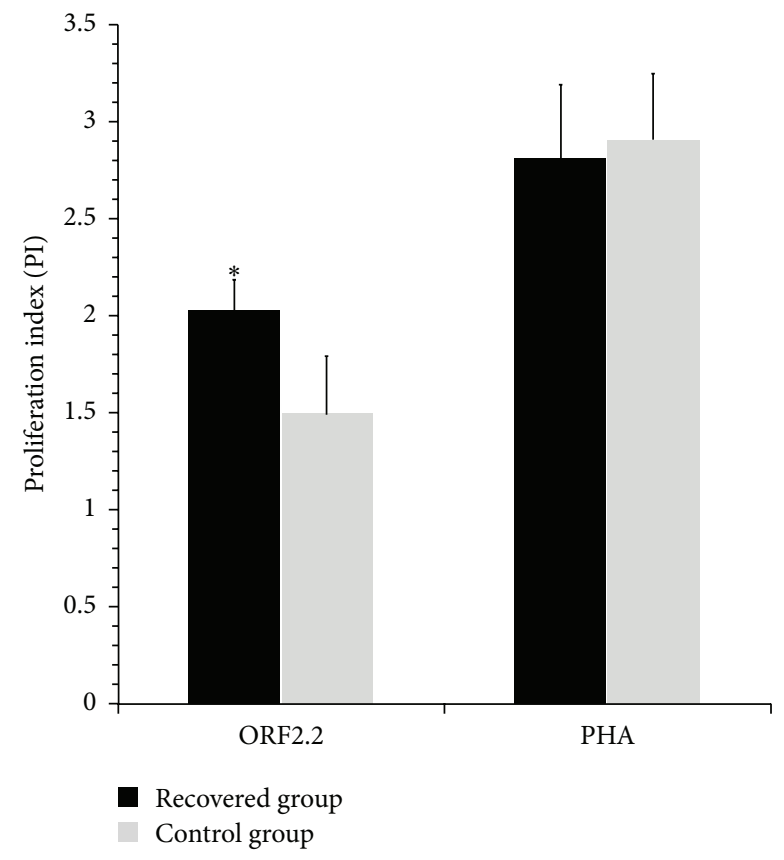

FIGURE 1: Cell proliferative responses in HEV-recovered individuals and control group. Proliferative responses to the truncated ORF2 protein are significantly higher in HEV-recovered group compared to the control group, while both groups showed good nonspecific stimulation with PHA. The results are shown as proliferation index (mean \pm SD PI).

group compared to the control group $(p<0.001)$ (Table 1 , Figure 2).

3.3. Cytokine Production in Responses to Truncated ORF2 Protein. Significant amounts of IFN- $\gamma$ and IL-12 cytokines but low amounts of IL-10 and IL-4 cytokines were produced following stimulation with the truncated ORF2 protein. Comparison between the two groups revealed no significant differences in the levels of IL-10 $(p=0.100)$ and IL-4 $(p=0.067)$, while IFN- $\gamma$ and IL-12 p70 were significantly higher in the recovered group compared to the control group $(p<0.001)$. Stimulation with PHA resulted in almost similar expression of all cytokines in the control and recovered groups, including $11.96 \pm 4.55$ and $11.29 \pm 3.9$ for IL-4 ( $p=$ NS), $199.45 \pm 108.43$ and $204.97 \pm 103.61$ for IL-10 ( $p=$ NS), $109.91 \pm 32.86$ and $103.22 \pm 25.9$ for IL-12 $(p=$ NS), and $410.37 \pm 46.96$ and $418.37 \pm 75.65$ for IFN $-\gamma(p=N S)$, respectively (Table 1, Figure 3).

\section{Discussion}

HEV causes self-limited acute hepatic infection worldwide and especially in developing countries where the disease is endemic and $30 \%$ to $80 \%$ of the adult population has antiHEV antibody [17]. The infection is more severe in pregnant women and patients with underlying liver problems and may progress to lethal fulminant hepatitis $[5,8]$. Information about HEV specific cellular immune responses could be useful in finding an effective way for development of HEV

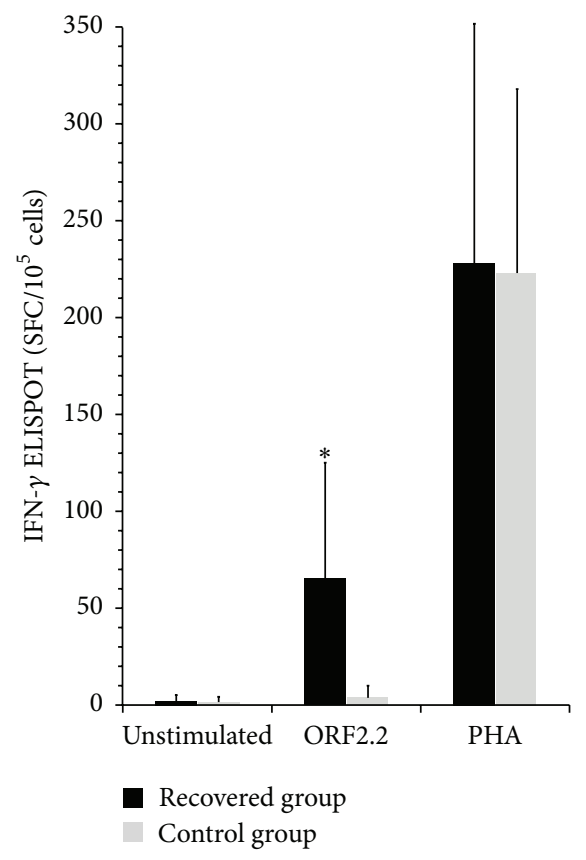

FIGURE 2: IFN- $\gamma$ ELISPOT responses in HEV-recovered and control groups. IFN- $\gamma$ ELISPOT responses to the truncated ORF2 protein are significantly higher in the recovered group compared to the controls, while both groups showed good nonspecific stimulation with PHA. The results are shown as spot forming cells per $10^{5}$ cells (SFC/10 5 cells).

vaccine, in particular as any protective vaccine for HEV infection is not still licensed [2,9]. However, some studies have evaluated HEV-specific cellular immune responses among different groups [6,18-20], but current information on cellular immune responses against HEV is not sufficient to prevent HEV infection. Therefore, this study aimed to evaluate HEV-specific cellular immune responses to the truncated ORF2 protein in the recovered individuals from HEV infection.

In the present study, a significant increase in the cell proliferation and IFN- $\gamma$ ELISPOT responses following stimulation with the truncated ORF2 protein were found in the HEV-recovered subjects, while both groups showed good nonspecific stimulation with PHA. Therefore, the increase in responses induced by truncated ORF2 protein was specific in the recovered group. These results indicate the antigenic nature of the truncated ORF2 protein. Suneetha et al. reported a similar increase in the HEV-specific T-cell responses by PBMCs obtained from recovered individuals from HEV infection. The stimulating antigen in their study was overlapping peptide pools and not the whole HEV ORF2 protein [20]. Regarding the full length ORF2 protein, Husain et al. presented similar results in acute hepatitis $\mathrm{E}$ patients compared to the controls [21]. It has been shown that ORF2 protein has several HTL (helper T-lymphocyte) dominant immunogenic regions and therefore it is a good antigen to elicit high and long-lasting specific anti-HEV immune responses [22]. The HEV-specific T-helper cell responses, especially against capsid protein, play a critical role in 


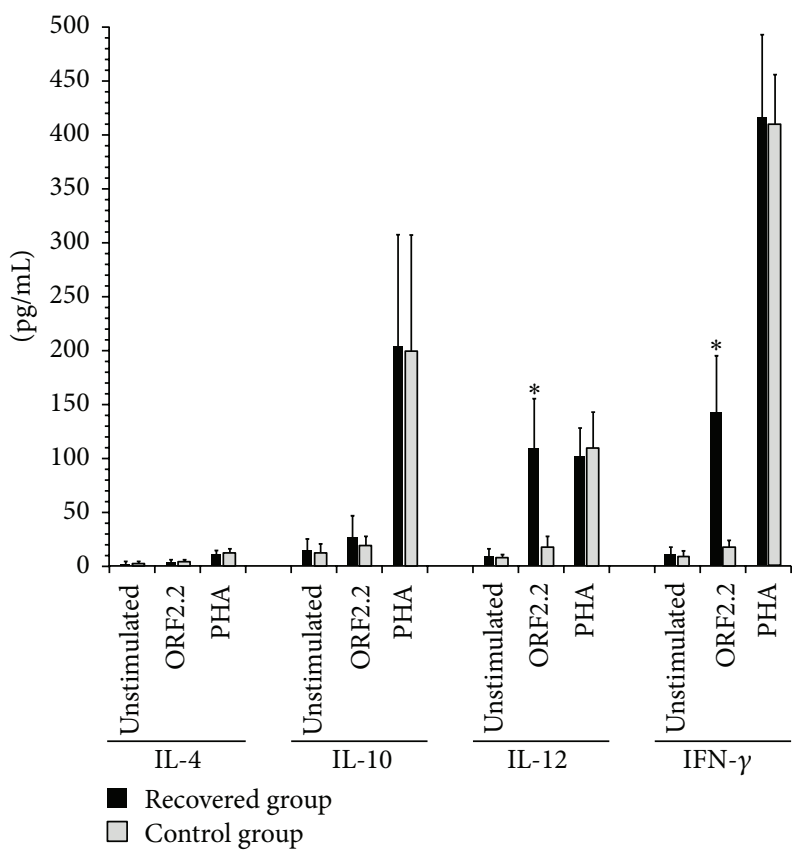

FIgURE 3: The levels of IL-4, IL-10, IL-12 p70, and IFN- $\gamma$ cytokines in HEV-recovered and control groups following stimulation with the truncated ORF2 protein. Significant amounts of IFN- $\gamma$ and IL12 cytokines but low amounts of IL-10 and IL- 4 cytokines were produced. IL-12 p70 and IFN- $\gamma$ cytokines production following stimulation with the truncated ORF2 protein was significantly higher in the recovered group compared to the control group, while there were no significant differences in the levels of IL-10 and IL4 between the two groups. Both groups showed almost similar expression of all cytokines following stimulation with PHA. Results are shown as mean $\pm \mathrm{SD} \mathrm{pg} / \mathrm{mL}$.

clearing and controlling viral infections, either directly through cytokines production or indirectly by activating cytotoxic T cells [1].

Production of T-helper type 1 (Th1) cytokines such as IFN- $\gamma$, TNF- $\alpha / \beta$, IL-2, IL-3, and IL-12 have been implicated in viral clearance or resistance to infection, while production of Th2 cytokines such as IL-4, IL-5, IL-13, IL-6, and IL-10 cytokines is associated with progression of the infection or viral persistence [23-28]. In the present study, the truncated ORF2 protein could significantly stimulate PBMCs to produce IFN- $\gamma$ and IL-12 but little or no IL-4. These results demonstrate that the Th1 responses are induced against the truncated ORF2 protein. The results of this study being consistent with those of others suggest that viral proteins that can shift immune responses to Th1, rather than Th2, may have a better chance of success as a vaccine candidate against HEV infection [29]. All participants in control and recovered groups showed almost similar expression of all cytokines following stimulation with PHA. Therefore, the increase in production of IFN- $\gamma$ and IL-12 cytokines following stimulation with truncated ORF2 protein was specific in the recovered group.

The results of the previous studies have shown that the production of Th1 cytokines such as IL-12 and IFN- $\gamma$ during
HEV infection results in self-limiting hepatitis E, suggesting the role of these cytokines in the recovery and clearance of hepatitis E, while the Th2 cytokines increase in fatal fulminant hepatitis E, especially during pregnancy $[18,27,30$, 31]. In Saravanabalaji et al. study, levels of IFN- $\gamma$ and IL-12 cytokines following stimulation of PBMCs by recombinant ORF2 protein were higher in recovered patients than those with fatal fulminant hepatitis E, while IL-10 was higher in fatal patients [30]. In Pal et al. study, high levels of IL-4 and IL-10 were observed in pregnant women with acute hepatitis E following stimulation of PBMCs with different peptides of HEV ORFs, while the level of IFN- $\gamma$ was low in this group [27]. In Srivastava et al. study, the IFN- $\gamma$ production following stimulation with ORF2 protein was higher in patients with acute HEV infection compared to control [6].

In this study, antigenic properties of the expressed ORF2 protein in E. coli BL21 cell were evaluated. Among the various microorganisms and systems available for protein production, E. coli BL21 containing pET-derived plasmids has become the most commonly used expression system because of its high expression capabilities, protein production with high purity, low cost, simple and fast cultivation, its wellknown genetics, and therefore ease of genetic manipulation [32]. However, there are a variety of factors that affect the expression level as well as the solubility and especially biological function of overexpressed proteins. One of the ways to improve the expression of foreign protein in E. coli is codon optimization, which results in selection of host favorite codons and elimination of high GC contents [33, 34]. By evaluating the antigenic properties and immunogenicity of the truncated ORF2 protein, it was indicated that this protein has biological function and can stimulate specific anti-HEV immune responses.

In conclusion, the truncated ORF2 protein is able to induce significant cellular immune responses and production of Thl cytokines in vitro and therefore can be introduced as a potential vaccine candidate for HEV infection. However further studies are required to evaluate this protein in vivo.

\section{Conflict of Interests}

The authors declare there is no conflict of interests in the content of this study.

\section{Authors' Contribution}

Fatemeh Farshadpour takes responsibility for the accuracy of the data. Reza Taherkhani and Fatemeh Farshadpour contributed equally to the design and performance of the study. Fatemeh Farshadpour and Manoochehr Makvandi drafted the paper. Nasrin Sharifi performed the statistical analysis. Ali Reza Samarbafzadeh, Saeed Tajbakhsh, Behrouz Naeimi, and Samad Akbarzadeh participated in the laboratory evaluation. Hamid Rajabi Memari performed the literature review. All authors have read and approved the paper.

\section{Acknowledgments}

The authors would like to acknowledge Grant no. 91111 supported financially by Deputy Research and Affairs of Ahvaz 
Jundishapur University of Medical Science, Ahvaz, Iran. The study was supported financially by the grant (no. 91111) provided by the Infectious and Tropical Diseases Research Center of Ahvaz Jundishapur University of Medical Sciences, Ahvaz, Iran.

\section{References}

[1] R. Aggarwal, R. Shukla, S. Jameel et al., “T-cell epitope mapping of ORF2 and ORF3 proteins of human hepatitis e virus," Journal of Viral Hepatitis, vol. 14, no. 4, pp. 283-292, 2007.

[2] N. J. de Oya, E. Escribano-Romero, A.-B. Blázquez et al., "Characterization of hepatitis $\mathrm{E}$ virus recombinant ORF2 proteins expressed by vaccinia viruses," Journal of Virology, vol. 86, no. 15, pp. 7880-7886, 2012.

[3] T. Yamashita, Y. Mori, N. Miyazaki et al., "Biological and immunological characteristics of hepatitis E virus-like particles based on the crystal structure," Proceedings of the National Academy of Sciences of the United States of America, vol. 106, no. 31, pp. 12986-12991, 2009.

[4] R. H. Purcell and S. U. Emerson, "Hepatitis E: an emerging awareness of an old disease," Journal of Hepatology, vol. 48, no. 3, pp. 494-503, 2008.

[5] L. Xing, J. C. Wang, T.-C. Li et al., "Spatial configuration of hepatitis E virus antigenic domain," Journal of Virology, vol. 85, no. 2, pp. 1117-1124, 2011.

[6] R. Srivastava, R. Aggarwal, S. Jameel et al., "Cellular immune responses in acute hepatitis E virus infection to the viral open reading frame 2 protein," Viral Immunology, vol. 20, no. 1, pp. 56-65, 2007.

[7] F. Farshadpour, R. Taherkhani, and M. Makvandi, "Prevalence of hepatitis E virus among adults in south-west of Iran," Hepatitis Research and Treatment, vol. 2015, Article ID 759589, 5 pages, 2015.

[8] F.-C. Zhu, J. Zhang, X.-F. Zhang et al., "Efficacy and safety of a recombinant hepatitis $\mathrm{E}$ vaccine in healthy adults: a large-scale, randomised, double-blind placebo-controlled, phase 3 trial," The Lancet, vol. 376, no. 9744, pp. 895-902, 2010.

[9] R. Taherkhani, F. Farshadpour, and M. Makvandi, "Design and production of a multiepitope construct derived from hepatitis E virus capsid protein," Journal of Medical Virology, vol. 87, no. 7, pp. 1225-1234, 2015.

[10] L. Wang and H. Zhuang, "Hepatitis E: an overview and recent advances in vaccine research," World Journal of Gastroenterology, vol. 10, no. 15, pp. 2157-2162, 2004.

[11] S. U. Emerson and R. H. Purcell, "Recombinant vaccines for hepatitis E," Trends in Molecular Medicine, vol. 7, no. 10, pp. 462466, 2001.

[12] M. Zhang, S. U. Emerson, H. Nguyen et al., "Immunogenicity and protective efficacy of a vaccine prepared from $53 \mathrm{kDa}$ truncated hepatitis $\mathrm{E}$ virus capsid protein expressed in insect cells," Vaccine, vol. 20, no. 5-6, pp. 853-857, 2001.

[13] R. Taherkhani and F. Farshadpour, "A new strategy for development of hepatitis E vaccine: epitope-based vaccines," Pathogen \& Infectious Disease, vol. 1, no. 1, article e933, 2015.

[14] T.-C. Li, N. Takeda, T. Miyamura et al., "Essential elements of the capsid protein for self-assembly into empty virus-like particles of hepatitis E virus," Journal of Virology, vol. 79, no. 20, pp. 12999-13006, 2005.

[15] R. Taherkhani, M. Makvandi, and F. Farshadpour, "Development of enzyme-linked immunosorbent assays using 2 truncated ORF2 proteins for detection of IgG antibodies against
Hepatitis E virus," Annals of Laboratory Medicine, vol. 34, no. 2, pp. 118-126, 2014.

[16] M. Majumdar, R. Ratho, Y. Chawla, and M. P. Singh, "Evaluation of antigenicity and cell mediated immunity of hepatitis E virus patients: using non radioactive MTT assay," Indian Journal of Medical Microbiology, vol. 31, no. 1, pp. 64-68, 2013.

[17] J. H. Hoofnagle, K. E. Nelson, and R. H. Purcell, "Hepatitis E," The New England Journal of Medicine, vol. 367, no. 13, pp. 12371244, 2012.

[18] A. S. Tripathy, R. Das, S. B. Rathod, and V. A. Arankalle, "Cytokine profiles, CTL response and T cell frequencies in the peripheral blood of acute patients and individuals recovered from hepatitis E infection," PLoS ONE, vol. 7, no. 2, Article ID e31822, 2012.

[19] S. B. Rathod and A. S. Tripathy, "Hepatitis E rORF2p stimulated and unstimulated peripheral expression profiling in patients with self-limiting hepatitis E infection," Journal of Immunology Research, vol. 2014, Article ID 565284, 10 pages, 2014.

[20] P. V. Suneetha, S. Pischke, V. Schlaphoff et al., "Hepatitis E virus (HEV)-specific T-cell responses are associated with control of HEV infection," Hepatology, vol. 55, no. 3, pp. 695-708, 2012.

[21] M. M. Husain, R. Aggarwal, D. Kumar, S. Jameel, and S. Naik, "Effector T cells immune reactivity among patients with acute hepatitis e," Journal of Viral Hepatitis, vol. 18, no. 10, pp. e603e608, 2011.

[22] T. Wu, J. Zhang, Z.-J. Su et al., "Specific cellular immune response in hepatitis E patients," Intervirology, vol. 51, no. 5, pp. 322-327, 2009.

[23] X. G. Fan, W. E. Liu, C. Z. Li et al., "Circulating Th1 and Th2 cytokines in patients with hepatitis C virus infection," Mediators of Inflammation, vol. 7, no. 4, pp. 295-297, 1998.

[24] M. Clerici and G. M. Shearer, " $\mathrm{A} \mathrm{T}_{\mathrm{H}} 1 \rightarrow \mathrm{T}_{\mathrm{H}} 2$ switch is a critical step in the etiology of HIV infection," Immunology Today, vol. 14, no. 3, pp. 107-111, 1993.

[25] X. G. Fan, J. Yakoob, X. J. Fan, and P. W. N. Keeling, "Enhanced T-helper 2 lymphocyte responses: immune mechanism of Helicobacter pylori infection," Irish Journal of Medical Science, vol. 165 , no. 1, pp. 37-39, 1996.

[26] R. L. Modlin and T. B. Nutman, "Type 2 cytokines and negative immune regulation in human infections," Current Opinion in Immunology, vol. 5, no. 4, pp. 511-517, 1993.

[27] R. Pal, R. Aggarwal, S. R. Naik, V. Das, S. Das, and S. Naik, "Immunological alterations in pregnant women with acute hepatitis E," Journal of Gastroenterology and Hepatology, vol. 20, no. 7, pp. 1094-1101, 2005.

[28] C. Ptaschinski, S. Mukherjee, M. L. Moore et al., "RSV-induced $\mathrm{H} 3 \mathrm{~K} 4$ demethylase KDM5B leads to regulation of dendritic cellderived innate cytokines and exacerbates pathogenesis in vivo," PLoS Pathogens, vol. 11, no. 6, Article ID e1004978, 2015.

[29] A. J. MacDonald, M. Duffy, M. T. Brady et al., "CD4 T helper type 1 and regulatory $\mathrm{T}$ cells induced against the same epitopes on the core protein in hepatitis $\mathrm{C}$ virus-infected persons," The Journal of Infectious Diseases, vol. 185, no. 6, pp. 720-727, 2002.

[30] S. Saravanabalaji, A. S. Tripathy, R. R. Dhoot, M. S. Chadha, A. L. Kakrani, and V. A. Arankalle, "Viral load, antibody titers and recombinant open reading frame 2 protein-induced Th1/Th2 cytokines and cellular immune responses in self-limiting and fulminant hepatitis E," Intervirology, vol. 52, no. 2, pp. 78-85, 2009. 
[31] R. Srivastava, R. Aggarwal, S. Sachdeva, M. I. Alam, S. Jameel, and S. Naik, "Adaptive immune responses during acute uncomplicated and fulminant hepatitis E," Journal of Gastroenterology and Hepatology, vol. 26, no. 2, pp. 306-311, 2011.

[32] M. Fakruddin, R. Mohammad Mazumdar, K. S. Bin Mannan et al., "Critical factors affecting the success of cloning, expression, and mass production of enzymes by recombinant E. coli," ISRN Biotechnology, vol. 2013, Article ID 590587, 7 pages, 2013.

[33] F. Farshadpour, R. Taherkhani, M. Makvandi et al., "Codonoptimized expression and purification of truncated ORF2 protein of hepatitis E virus in Escherichia coli," Jundishapur Journal of Microbiology, vol. 7, no. 7, Article ID e11261, 2014.

[34] C. Elena, P. Ravasi, M. E. Castelli, S. Peirú, and H. G. Menzella, "Expression of codon optimized genes in microbial systems: current industrial applications and perspectives," Frontiers in Microbiology, vol. 5, article 21, 2014. 


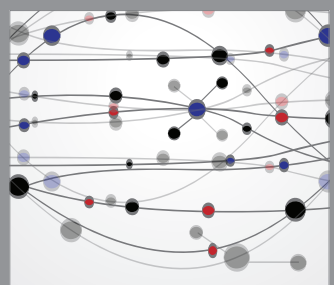

The Scientific World Journal
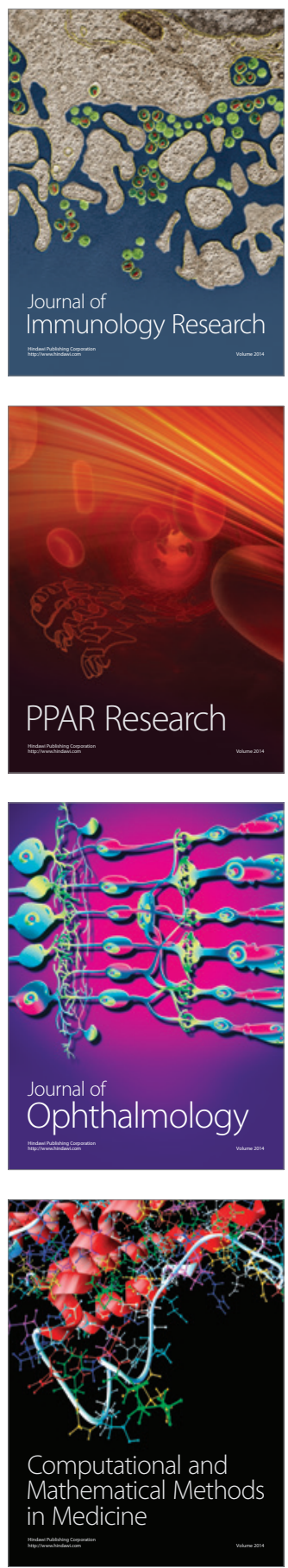

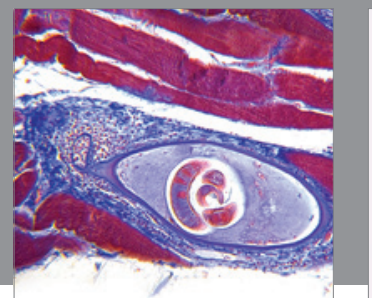

Gastroenterology

Research and Practice
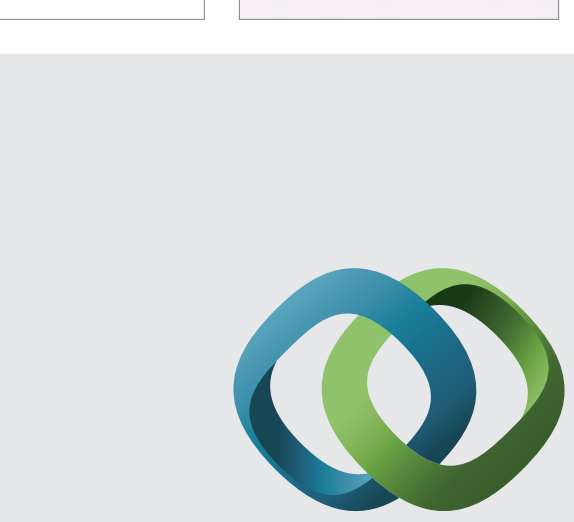

\section{Hindawi}

Submit your manuscripts at

http://www.hindawi.com
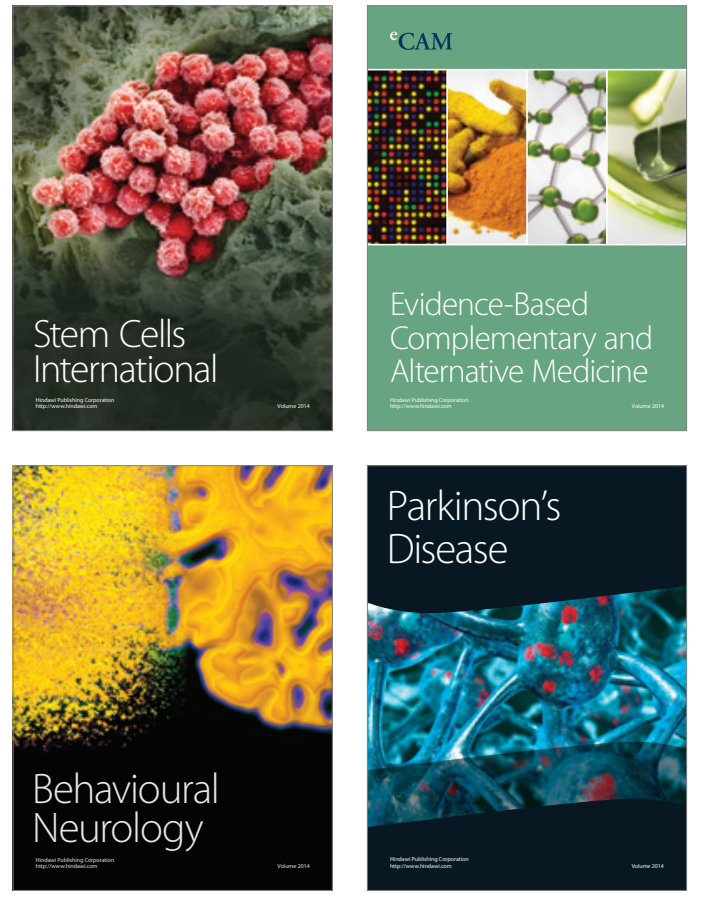
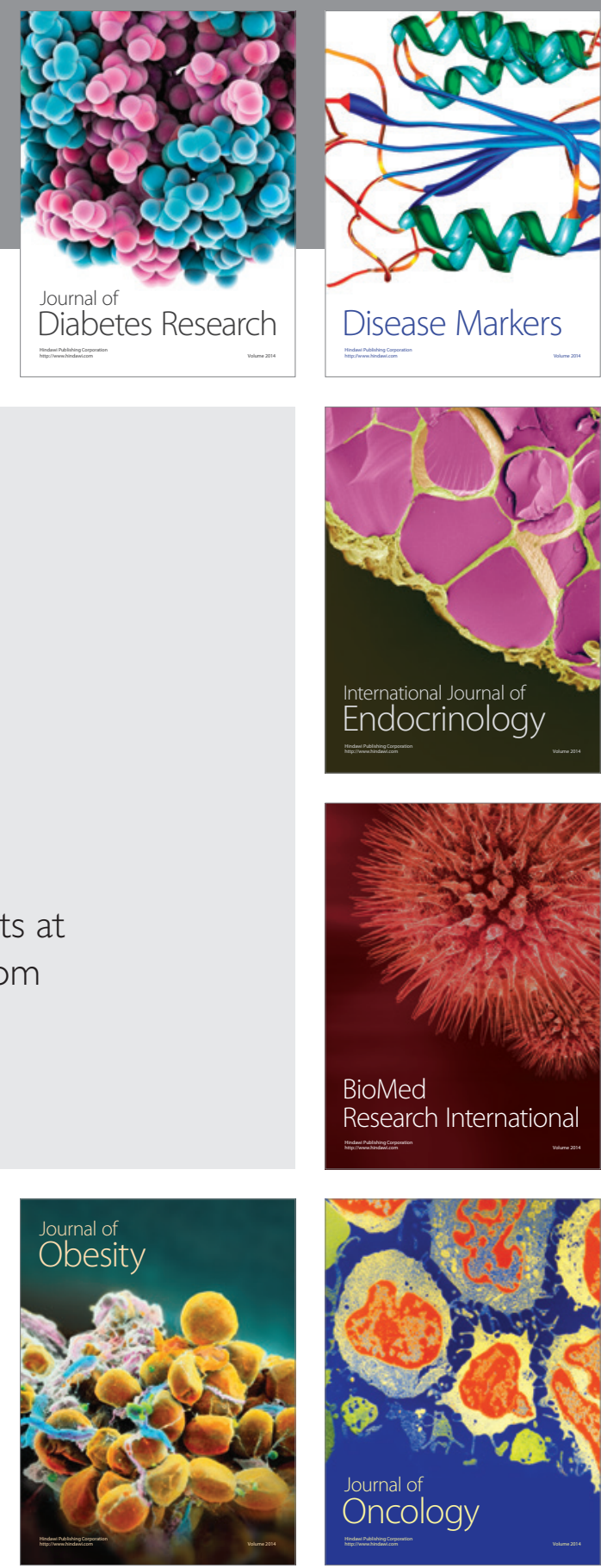

Disease Markers
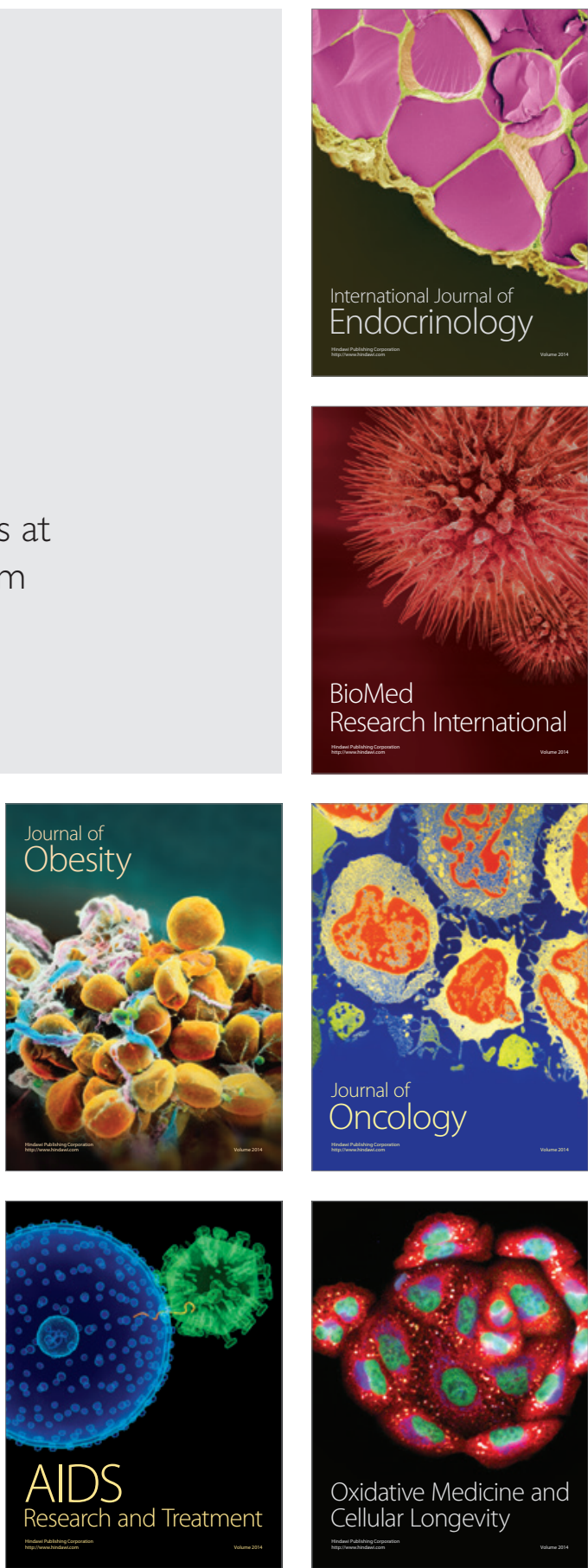